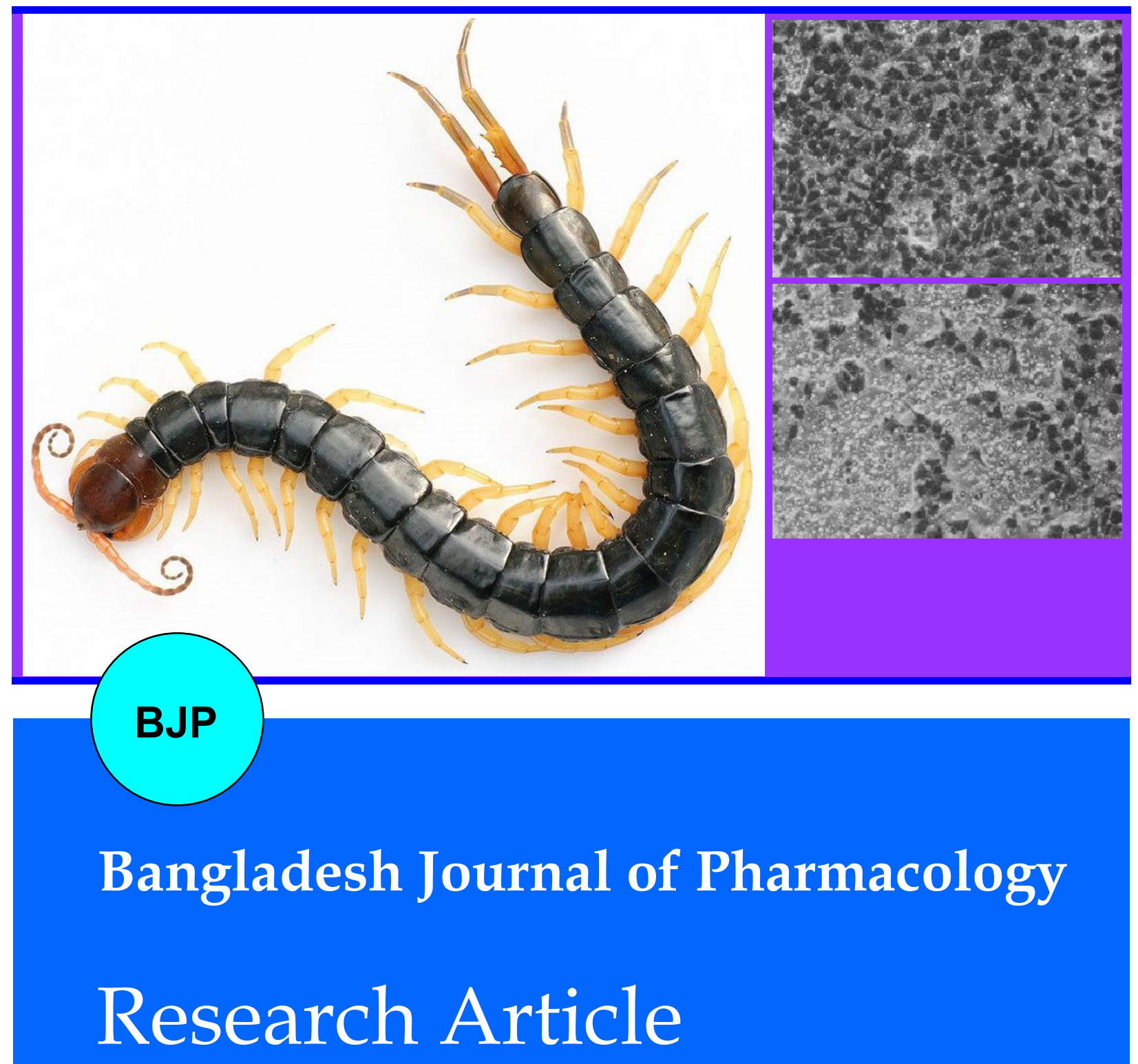

\title{
Centipede Scolopendra suppresses cell growth in human epidermoid carcinoma cell A431
}


Abstracted/indexed in Academic Search Complete, Asia Journals Online, Bangladesh Journals Online, Biological Abstracts, BIOSIS Previews, CAB Abstracts, Current Abstracts, Directory of Open Access Journals, EMBASE/Excerpta Medica, Global Health, Google Scholar, HINARI (WHO), International Pharmaceutical Abstracts, Open J-gate, Science Citation Index Expanded, SCOPUS and Social Sciences Citation Index;

ISSN: $1991-0088$

\section{Centipede Scolopendra suppresses cell growth in human epidermoid carcinoma cell A431}

\section{Lei Zheng, Hao He, Xuji Shen and Yanping Sun}

\section{School of Pharmaceutical Sciences, Xi'an Medical University, Xi'an, Shaanxi Province 710021, China.}

\begin{tabular}{|c|c|}
\hline \multicolumn{2}{|l|}{ Article Info } \\
\hline Received: & 11 May 2017 \\
\hline Accepted: & 28 July 2017 \\
\hline Available Online: & 20 August 2017 \\
\hline \multicolumn{2}{|c|}{ DOI: 10.3329/bjp.v12i3.32525 } \\
\hline \multicolumn{2}{|c|}{$\begin{array}{l}\text { Cite this article: } \\
\text { Zheng L, He H, Shen X, Sun Y. Centi- } \\
\text { pede Scolopendra suppresses cell } \\
\text { growth in high-EGFR expression cell } \\
\text { A431. Bangladesh J Pharmacol. 2017; } \\
\text { 12: 299-307. }\end{array}$} \\
\hline
\end{tabular}

\begin{abstract}
The aim of this study was to examine the anti-proliferation and anti-migration effect of Centipede Scolopendra extracts (CSE) on human epidermoid carcinoma cells (high-EGFR expression) A431 and elucidate the underlying signaling mechanisms. MTT and colony formation assays were used. Migration and invasion potential of A431 cells were examined by wound-healing assays and matrigel invasion chamber assays. To investigate the underlying molecular mechanisms, we used ELISA to analyze the expression of EGF, Western blotting to analyze the expression of MMP2 (matrix metalloproteinase 2), MMP9 and EGFR, PCR to analyze the mRNA expression of EGFR pretreated with CSE. The results showed that CSE effectively inhibited the proliferation of A431. Furthermore, CSE-mediated cell cycle arrest in S phase. We also observed that CSE treatment led to down-regulation of MMP2 and MMP9 and suppress the migration and invasion in A431. CSE exerted its antiproliferation and anti-migration by targeting EGFR and related metastasis factors, thus could be a useful therapeutic candidate for high-EGFR expression cancer intervention.
\end{abstract}

\section{Introduction}

Now-a-days, insects have proved to be more important as sources of drugs from the Traditional Chinese Medicine. Centipedes, the oldest terrestrial arthropods and the ecologically important group of soil and leaf litter predators, have been used to treat a variety of conditions, such as spasm, seizure, poisonous nodules, diphtheria (Undheim and King, 2011; Ma et al., 2015), and inhibit the growth of tumor both in vitro and in vivo (Lee et al., 2015). Centipedes have venom glands in their first pair of limbs and their venoms contain a large number of components with different biochemical and pharmacological properties not only to paralyze and kill preys but also to defend against predators. The venom composition and structure of centipedes are largely unknown and recent studies show that serotonin, histamine, lipids, polysacchardides and polypeptides have been found from the crude extracts of centipede venom glands (Liu et al., 2012).

Cancer death is not only a result of uncontrolled tumor growth but also of promoted cancer metastasis, and thus blocking the growth and metastasis of cancer has been the key strategies in anti-cancer therapy. Epidermal growth factor receptor (EGFR) normally promotes cell growth and development, and when mutated, allows the uncontrolled growth of cells that is the hallmark of cancer (Goldman et al., 1996). Research shows that EGFR in tumor tissues have close relationship with the metastasis and poor prognosis of cancer (Sirkisoon et al., 2016). EGFR is a transmembrane growth-factorreceptor tyrosine kinase that belongs to the HER/ErbB protein family, has an ATP-binding site plus tyrosine kinase activity and is capable of phosphorylating itself as well as other proteins (Li et al., 2009). EGFR increment is an important promoting factor in the infiltration and transition of carcinoma. The elevated level of the 
EGFR, and/or its cognate ligands have been identified as a common component of numerous cancer types including epithelial and mesenchymal lineages and appear to be frequently related to the development of cancer (Nicholson et al., 2001).

Upon activation by distinct ligands, the intrinsic kinase is activated, which results in receptor homo- or heterodimerization with another member of the HER/ErbB family, followed by tyrosyl-phosphorylation of EGFR itself and numerous intermediary effect or molecules (Hynes, 2016; Wells, 1999). These tyrosine phosphorylated sites allow proteins to bind through their Src homology 2 (SH2) domains leading to the activation of downstream signaling cascades such as the Ras/ mitogen activated protein kinase (MAPK) pathway and the phosphoinositide-3 kinase (PI3K)/AKT pathway (Magkou et al., 2008; Yarden and Sliwkowski, 2001; Zhan et al., 2012). The biological responses to EGFR signaling are pleiotropic including regulating cellular proliferation, angiogenesis, inhibition of apoptosis and differentiation, which play critical roles in epidermoid carcinoma pathogenesis (Huang and Harari, 1999; Oliveira et al., 2006). Thus, EGFR and its downstream signaling molecules have emerged as promising targets for cancer therapy (Woodburn, 1999).

Human epidermoid carcinoma cells A431 commonly overexpress EGFR which induces rapid tyrosine phosphorylation of proteins (Merlino et al., 1984). Therefore, high-EGFR expression cells A431 cells are adopted in this study.

Therefore, in the present work, the authors evaluated the anti-tumor activities of Centipede Scolopendra extract (CSE), and the obtained results showed that CSE could alter EGFR kinase activity examined by LANCETM assay (Ma et al., 2015). We investigated the mechanism of CSE targeting EGFR signaling pathway in cancer treatment.

\section{Materials and Methods}

\section{Reagents}

Adult specimens of Centipede Scolopendra (Scolopendra subspinipes mutilans) were purchased from the Laobanxing Pharmacy in Shaanxi Province of China. Identification of the specimens was done at the Pharmacognosy Laboratory, Department of Pharmacy, $\mathrm{Xi}^{\prime}$ an Jiaotong University where a voucher specimen was deposited. Dulbecco's minimal essential medium (DMEM), Ham's F12 nutrient medium, dimethylsulfoxide (DMSO), and trypsin were purchased from the Sigma-Aldrich (USA). Annexin V-FITC apoptosis detection kit and Hoechst 33258 staining kit were purchased from the Beyotime Institute of Biotechnology (China). Protease inhibitor cocktail and phosphatase inhibitor cocktail were purchased from the Roche (Switzerland). Anti-EGFR, anti-phospho-EGFR, antiMMP2, anti-MMP9 antibody were purchased from the Cell Signaling Technology (USA). Rabbit anti-GAPDH was purchased from the Santa Cruz Biotech (USA). Rabbit anti-mouse IgG, BCA protein assay reagent kit and SuperSignal ${ }^{\circledR}$ West Pico were purchased from the Pierce Biotech (USA).

\section{Extraction method of CSE}

Centipede Scolopendra was crushed into fine powder. Initially, $50 \mathrm{~g}$ Centipede Scolopendra was decocted in $1,500 \mathrm{~mL}$ ethanol solution $(3 / 2$ by $\mathrm{v} / \mathrm{v}$; ethanol/water) for 1 hour, and then filtered to obtain the filtrate concentrate. The filter residue was then put into $750 \mathrm{~mL}$ ethanol solution ( $3 / 2$ by $v / v$; ethanol/water), and the process for collecting the concentrate was repeated. Both filtrate concentrates were combined and filtered once again. Finally, the extract was concentrated by the use of rotary evaporator.

\section{Cell culture}

A431 cells were obtained from the Shanghai Institute of Cell Biology in the Chinese Academy of Sciences and were cultured in F12 supplemented with $10 \%$ (v/v) fetal bovine serum and incubated at $37^{\circ} \mathrm{C}$ with $5 \% \mathrm{CO}_{2}$. In experiments, cells were used during the linear phase of growth.

\section{Cell viability assay}

The effect of CSE on A431 cell proliferation was evaluated by the MTT assay. Exponentially growing cells were seeded into 96-well plates at a density of $2 \times$ $10^{4}$ cells per well in the medium. 24 hours after seeding, cells were treated with CSE at various concentrations for 48 hours. Then, $20 \mu \mathrm{L}$ of MTT $(5 \mathrm{mg} / \mathrm{mL})$ was added to each well and incubated at $37^{\circ} \mathrm{C}$ for 4 hours. After the removal of medium, $150 \mu \mathrm{L}$ of DMSO was added to each well, and the optical density of cells was determined with a microplate reader (Bio-RAD instruments, USA) at $490 \mathrm{~nm}$ and expressed as absorbance value.

\section{Colony formation assay}

A431 cells were plated in 6-well plates (100 cells per well). After incubating for 24 hours, the cells were treated with CSE at various concentrations for 10 to 15 days. Colonies with cell numbers of $>50$ cells per colony were photographed and counted after staining with $0.01 \%$ crystal violet solution. All the experiments were performed in triplicate wells in 3 independent experiments.

\section{Propidium iodide staining assay}

Cell death was measured by propidium iodide staining assay. A431 cells were trypsinized after the treatment with CSE at various concentrations for different time 
periods and then cells were collected and suspended in $1 \mathrm{~mL}$ PBS. Cells were stained with $0.5 \mathrm{~mL}$ of staining solution $(50 \mathrm{mg} / \mathrm{mL}$ propidium iodide, $100 \mathrm{mg} / \mathrm{mL}$ RNase, $0.2 \%$ Triton-100) and cells were incubated at $37^{\circ}$ $\mathrm{C}$ for $30 \mathrm{~min}$ in the dark. Cell death was measured by flow cytometry (Beckman Coulter, Inc., USA).

\section{Cell cycle}

For the analysis of cell cycle arrest, A431 cells were stained with propidium iodide as previously described. Cells were treated with CSE at various concentrations respectively. After treatment for 48 hours, cells were trypsinized, collected, and washed with PBS, then cells were subsequently fixed in $70 \%$ ethanol, incubated with RNase $(50 \mu \mathrm{g} / \mathrm{mL})$ and propidium iodide $(60 \mu \mathrm{g} / \mathrm{mL})$ protecting from light at room temperature for $30 \mathrm{~min}$. The cell suspension was analyzed by the flow cytometer.

\section{Wound-healing assay}

A431 cells were planted into a 6-well plate and allowed to grow to $70 \%$ confluency in complete medium. Cells were then serum starved for 24 hours, and cell monolayers were carefully scratched an artificial "wound" at 0 hour with a pipette tip. Wounded monolayers were then washed to remove floating cells and photographed under an inverted microscope. Cells were incubated in medium with or without concentrations of CSE. Cell migration into the wound surface and the average distance of migrating cells were observed at different times using a phase contrast microscope.

\section{Migration and invasion assays}

In vitro cell migration assays were performed using transwell chambers ( $8 \mu \mathrm{M}$ pore size; Millipore, USA). Cells were allowed to grow to sub-confluency (75-80\%) and were serum-starved for 24 hours. After detachment with trypsin, cells were washed with PBS, and resuspended in serum-free medium. Cell suspension (2 $\times 10^{5}$ cells $/ \mathrm{mL}$ ) was added to the upper chamber with or without concentrations of CSE in $400 \mu \mathrm{L}$ of $1 \%$ BSA RPMI 1640 medium. The bottom chamber contained medium with 10\% FBS RPMI 1640 medium to serve as a chemoattractant to induce invasion. For the screen, after 24 hours the cells that had not migrated were removed from the upper face of the filters using cotton swabs. To determine the number of migratory cells, the invaded cells were fixed with $100 \%$ methanol and then stained with $0.2 \%$ crystal violet (Beijing Chemical Works, China). Images of three different fields were captured from each membrane and the number of migratory cells was counted using a phase contrast microscope. The mean of triplicate assays for each experimental condition was used. Similar inserts coated with $100 \mu \mathrm{L}$ (1 $\mathrm{mg} / \mathrm{mL}$ ) matrigel (Becton-Dickinson, USA) were used to determine invasive potential in the invasion assay.

\section{EGF secretion in vitro}

Exponentially growing cells were seeded into 96-well plates at a density of $2 \times 10^{4}$ cells per well in the medium. 24 hours after seeding, cells were treated with CSE at various concentrations for 48 hours, and then cell culture mediums were collected, centrifuged at 12,000 $\mathrm{g}, 4^{\circ} \mathrm{C}$ for $10 \mathrm{~min}$. EGF protein concentrations were quantified by a commercially available EGF-ELISA kit. ODs were measured at $450 \mathrm{~nm}$ according to the manufacturer's instructions (Shimamura et al., 2001).

\section{Western blot analysis}

A431 cells were exposed to CSE and then analyzed through Western blotting. Cells, treated with CSE at various concentrations for 48 hours, were lysed with RIPA lysis buffer containing protease inhibitor cocktail and phosphates inhibitor cocktail on ice for $30 \mathrm{~min}$, then lysis buffer was collected and centrifuged at 12,000 $\mathrm{xg}, 4^{\circ} \mathrm{C}$ for $10 \mathrm{~min}$. The protein lysates were resolved by SDS-PAGE, and separated proteins were transferred to PVDF membranes and blocked with 5\% skimmed milk for 2 hours. Then, the membranes were incubated with specific primary antibodies overnight at $4^{\circ} \mathrm{C}$ and incubated with the relevant secondary antibodies at 1:10,000 dilutions at room temperature for 2 hours in accordance with the manufacturer's instructions. Finally, the blots were detected by Immobilon $\AA$ Western (Millipore Corporation, USA)

\section{PCR}

The mRNA expression levels of EGFR in the cells were quantitatively analyzed by reverse transcription polymerase chain reaction (RT-PCR), as described previously (Cao et al., 2013). GAPDH was measured as an invariant housekeeping gene for an internal control. Amplified cDNA bands were detected by Goldview staining (RuiTaibio, Beijing, China) and the quantities of mRNA were evaluated using the Gene Genius imaging system (Syngene, Cambridge, UK).

Primer sequences for the analysis are shown as follows:

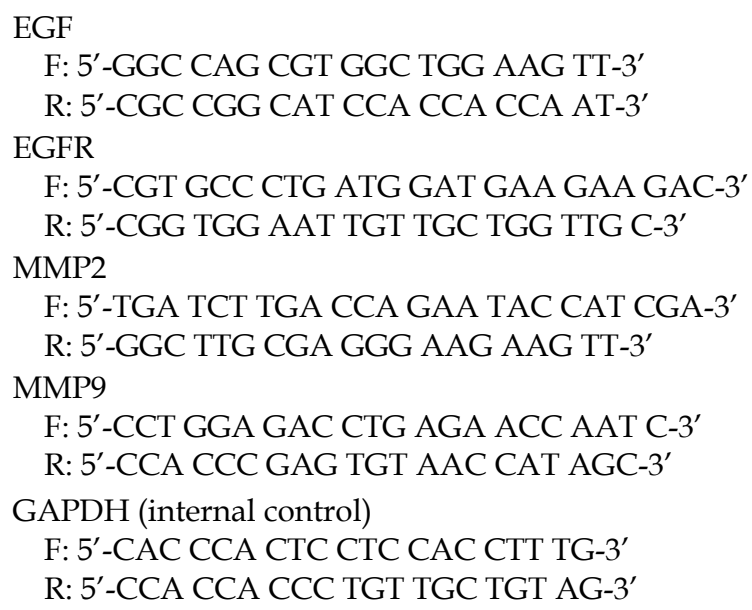




\section{Statistics}

All data were obtained from at least three independent experiments and expressed as mean \pm SEM. Comparisons of the different groups were performed with Student's t-test. $\mathrm{p}<0.05$ was considered the minimal level of significance.

\section{Results}

\section{Proliferation and colony formation of A431 cells}

The effects of CSE on the growth of A431 cells were evaluated by MTT assay. CSE showed significant antiproliferative effects in human epidermoid carcinoma A431 cells in a dose-dependent manner, as shown in Figure 1A. The 48 hours $50 \%$ inhibitory concentration (IC 50 ) of CSE on A431 was $0.3 \mathrm{mg} / \mathrm{mL}$.

In addition, the colony formation assay showed that CSE generated a significantly lower number of colonies in comparison with the control (Figure 1B). These findings indicated that CSE had potential antitumor properties in A431 in vitro.

Cells stained with propidium iodide were considered as dead cells. Each panel showed that CSE-treated cells increased propidium iodide uptake, indicating cell death was increased. In addition, we also observed that CSE induced cell death in A431 cells in a dosedependent manner. These data were consistent with results from cell growth inhibition studies above using the MTT, confirming that CSE could act as an inhibitor of A431 cell growth.

\section{Effect on cell cycle}

To gain further insight into the mechanisms underlying the cytotoxic effects of CSE on A431 cells, we next investigated the effect of this compound on cell cycle progression. Cells treated with $0,0.1,0.2$ and $0.3 \mathrm{mg} /$ $\mathrm{mL}$ of CSE for 48 hours displayed a $S$ phase arrest. As shown in Figure 2, the percentage of cells accumulated in $S$ phase was 20.6, 41.1, 46.2 and $63.0 \%$ following treatment with $0,0.1,0.2$ and $0.3 \mathrm{mg} / \mathrm{mL}$ of CSE, respectively. Accumulation of $S$ phase cells was maximal in the control group and declined to go with higher concentration. The decrease in the number of G1 phase cells was $70.7,42.9,33.2$, and $25.4 \%$ with $0,0.1$, 0.2 and $0.3 \mathrm{mg} / \mathrm{mL}$ of CSE for 48 hours was accumulation of cells in the $S$ phase. These results indicated that CSE-mediated cell death in A431 cells was due to inducing a $S$ phase cell cycle arrest in part.

\section{Cell migration}

To investigate the effect of CSE on cell migration, wound-healing (scratch motility) and transwell migration assays were used. Confluent monolayers of cells were scratched to form wounds, then cultured in the presence of various concentrations of $\operatorname{CSE}(0,0.1,0.2$

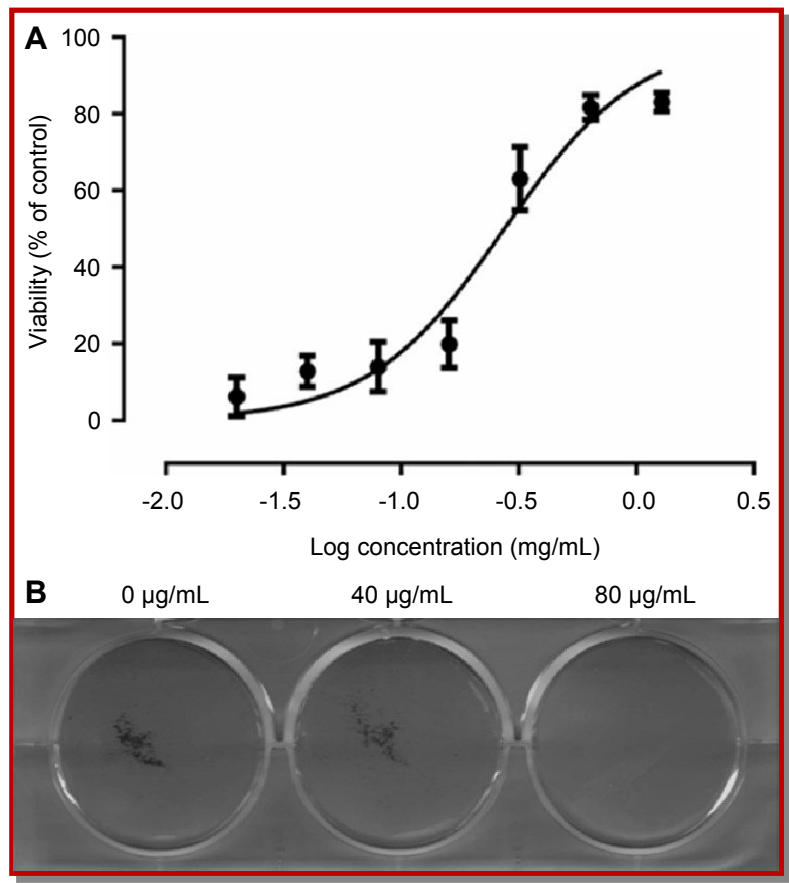

Figure 1: CSE suppressed tumor cell proliferation and colony formation

A, Effect of CSE on proliferation of human epidermoid carcinoma cells A431. A431 Cells were treated by CSE at indicated concentrations for 48 hours. The cell proliferation was measured using the MTT assay. Data were represented as the means \pm SEM from three repeated experiments. B, Effect on colony formation of A431 cells by CSE

and $0.3 \mathrm{mg} / \mathrm{mL}$ ), and observed at a different time after cell monolayers had been wounded. As shown in Figure 3, CSE-induced cells moved slowly compared with the control group in a dose-dependent manner. Similar results were obtained from the transwell invasion assays. Millicell was also used to determine the inhibitory effect of CSE on A431 cell migration. Results showed that after 48 hours treatment with various concentrations of ESMC 0, 0.1, 0.2 and $0.3 \mathrm{mg} /$ $\mathrm{mL})$, the cell number on the lower surface of the membrane decreased in a dose-dependent manner (Figure 4). Taken together, our data suggested that CSE could impair A431 cells migration.

\section{Invasion of A431 cells}

The possible effect of CSE on cell invasion was examined using matrigel-coated chambers. Cells were treated with various concentrations of $\operatorname{CSE}(0,0.1,0.2$ and $0.3 \mathrm{mg} / \mathrm{mL}$ ) for 48 hours on the upper side, and then allowed to migrate through a membrane coated with matrigel. As shown in Figure 5, CSE inhibited the invasion ability of A431 cells in a dose-dependent manner. These data were consistent with results we found above.

\section{EGF/EGFR signaling protein expression}

ELISA for EGF showed that CSE could significantly inhibit EGF secretion of A431 cells in a dose-dependent 


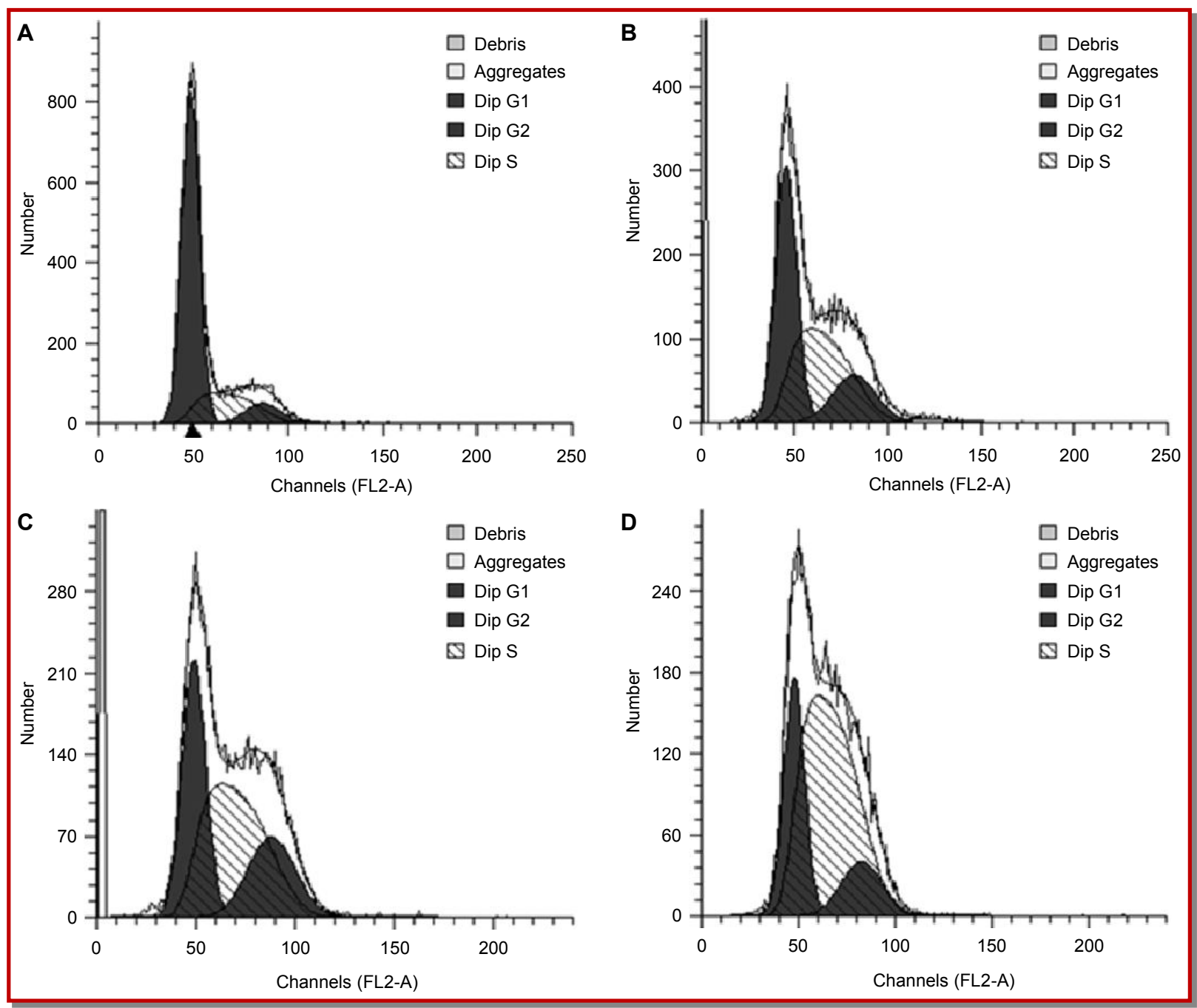

Figure 2: CSE-mediated cell cycle arrest in $S$ phase

A431 cells treated with A 0, B 0.08, C 0.16, and D $0.32 \mathrm{mg} / \mathrm{mL}$ of CSE for 48 hours followed by staining with PI for flow cytometric analysis. Histograms reveal number of cells/channel (y axis) versus DNA content ( $x$ axis). The values showed the percentage of cells in the indicated phases of cell cycle. The graph depicting the results of flow cytometric distribution of cells in different phases of cell cycle, displaying that Brucine arrests S phase. The data shown are representative of three independent experiments with the similar results

manner compared with the control group (Figure 6A) by ELISA. In order to test the effect of CSE on EGFR, pEGFR, MMP-2, MMP-9 in A431 cells, protein expression was analyzed by western blotting. Figure $6 \mathrm{~B}$ showed protein expression in tumor cells, the results indicated that the EGFR expression was decreased in the CSEtreated groups in contrast to the control group. Therefore we investigated the effect of CSE on EGFR signaling pathway in A431 cells. As shown in Figure 6C, treatment of CSE significantly decreased phosphorylation of EGFR, ERK1/2 and AKT in A431 cells. The results suggested that EGFR pathway phosphorylation could be down-regulated by CSE in a dose-dependent manner.

\section{Effect on mRNA expression}

RT-PCR was carried out to investigate whether CSE could influence the synthesis of EGF, EGFR, MMP2 and MMP9 transcript. Compared to the negative control, the mRNA expression of EGF, EGFR, MMP2 and MMP9 in the CSE-treated groups was significantly downregulated in a dose-dependent manner in A431 cells (Figure 7). And the mRNA levels of EGF, EGFR, MMP2 and MMP9 were significantly down-regulated at a dose -effect relationship in the CSE-treated cells. These indicated that CSE could regulate the mRNA levels of EGF, EGFR, MMP2 and MMP9.

\section{Discussion}

The results of the present study confirm that CSE could markedly reduce the activity of EGFR kinase activity, consequently affect the cell proliferation of A431 cells. 


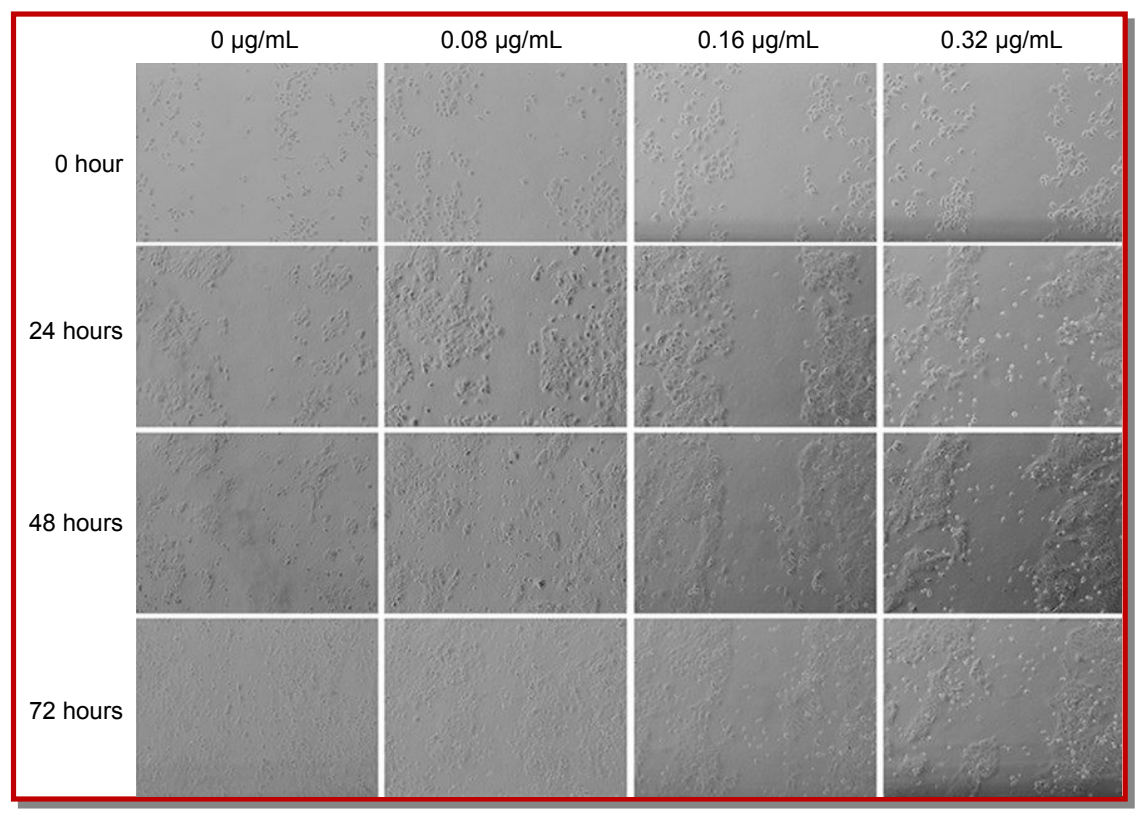

Figure 3: CSE inhibited migration of A431 cells

Photographs of wound of cells treated with CSE. Confluent monolayers of A431 cells were scarred and pretreatment with CSE, the migrating cells into the wound surface were photographed

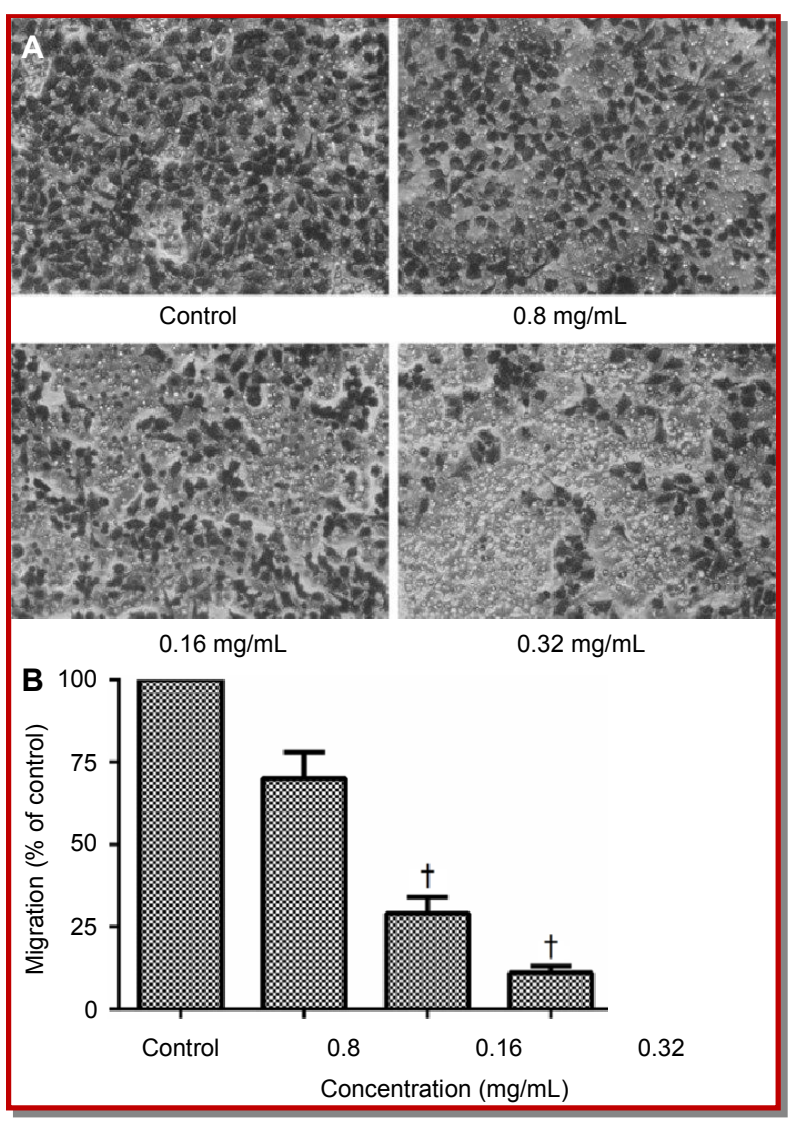

Figure 4: CSE inhibited migration of A431 cells

A, Photographs showed the cell migration through the polycarbonate membrane treated with concentrations of CSE stained by $0.2 \%$ crystal violet. B, Quantification of the number of cells migrating through the polycarbonate membrane. Statistically significant changes at $t \mathrm{p}<0.01 \mathrm{vs}$. the control group
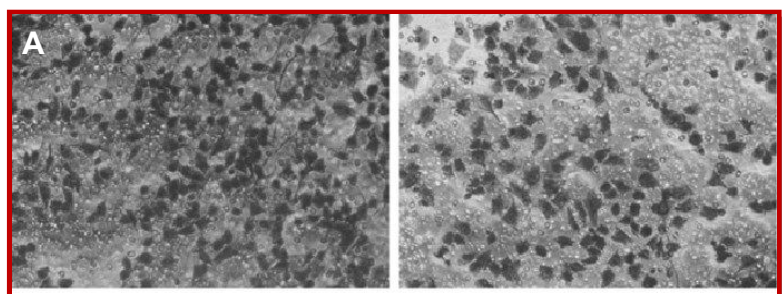

Control

$0.8 \mathrm{mg} / \mathrm{mL}$

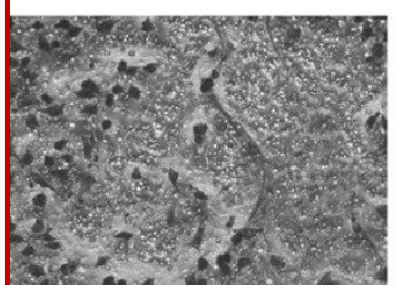

$0.16 \mathrm{mg} / \mathrm{mL}$

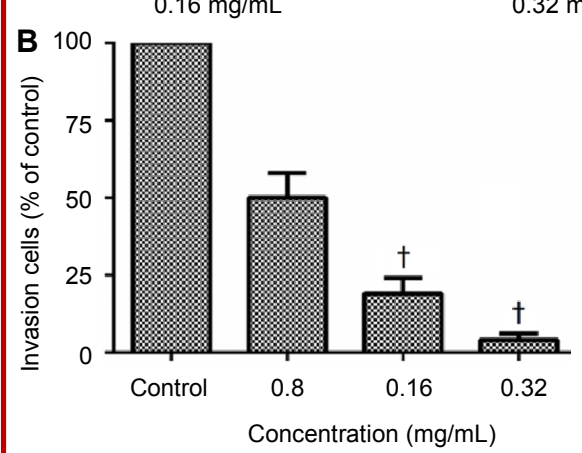

Figure 5: CSE inhibited invasion of A431 cells

A, Photographs showed the cell invasion through the matrigel-coated polycarbonate membrane stained by $0.2 \%$ crystal violet. B, Quantification of the cell invasion assay. Data were represented as means \pm SEM at least three independent experiments. Statistically significant changes at $\mathrm{tp}<0.01$ vs. the control group 


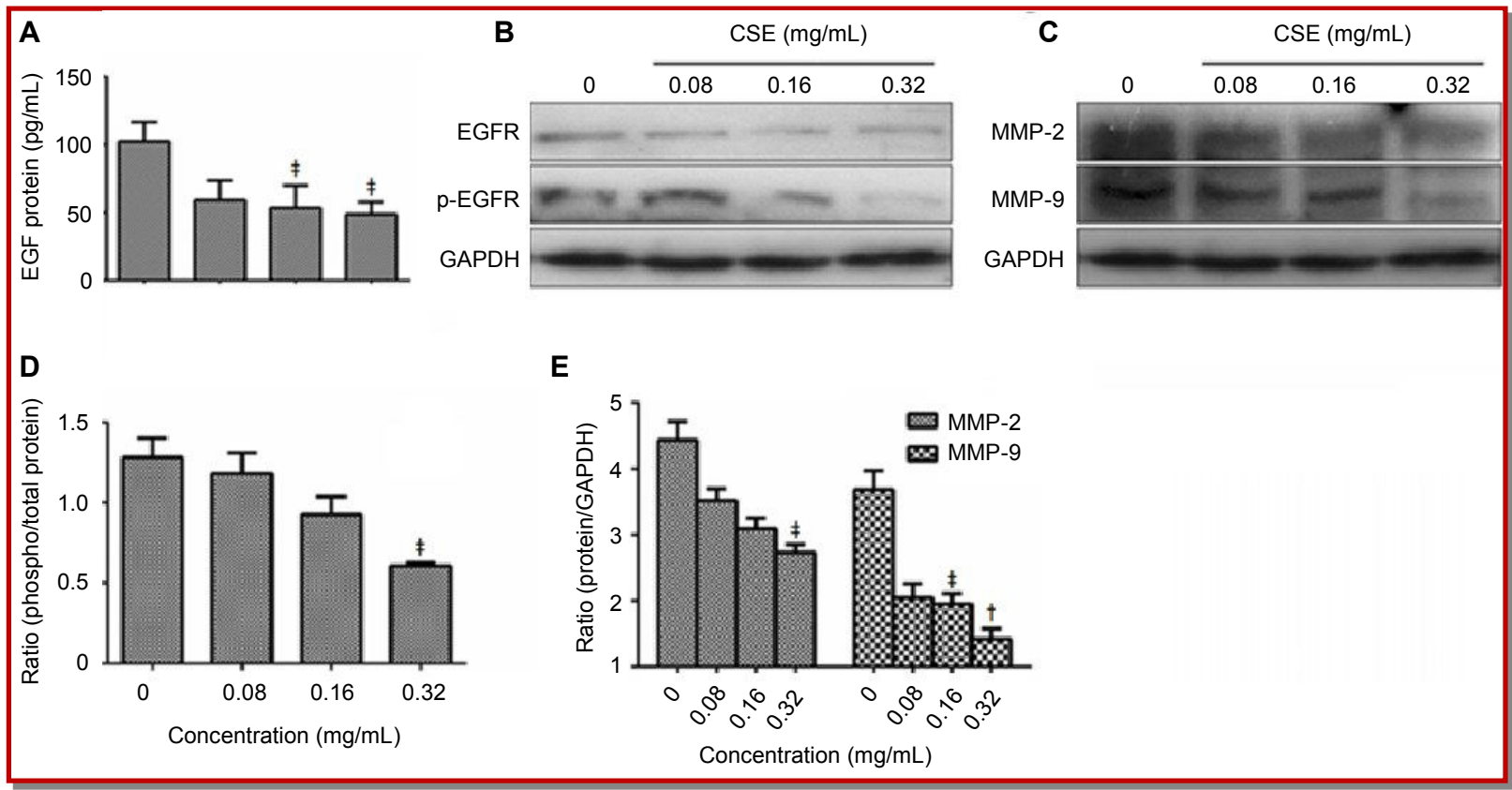

Figure 6: Effect of CSE on protein expression

A431 cells were treated with various concentrations of CSE for 48 hours, the concentrations of EGF in the supernatant were determined by ELISA, then equal amounts of lysates were analyzed by western blotting using individual antibodies. A, CSE could inhibit EGF production in a dosedependent manner at cell samples compared with the control group. B, CSE inhibited activated EGFR expression in A431 cells. C, CSE downregulated expression of proteins related to metastasis. D and E, quantification of B and C. Data were represented as means \pm SEM at least three independent experiments. Statistically significant changes at $\neq \mathrm{p}<0.05, \mathrm{tp}<0.01 \mathrm{vs}$. the control group

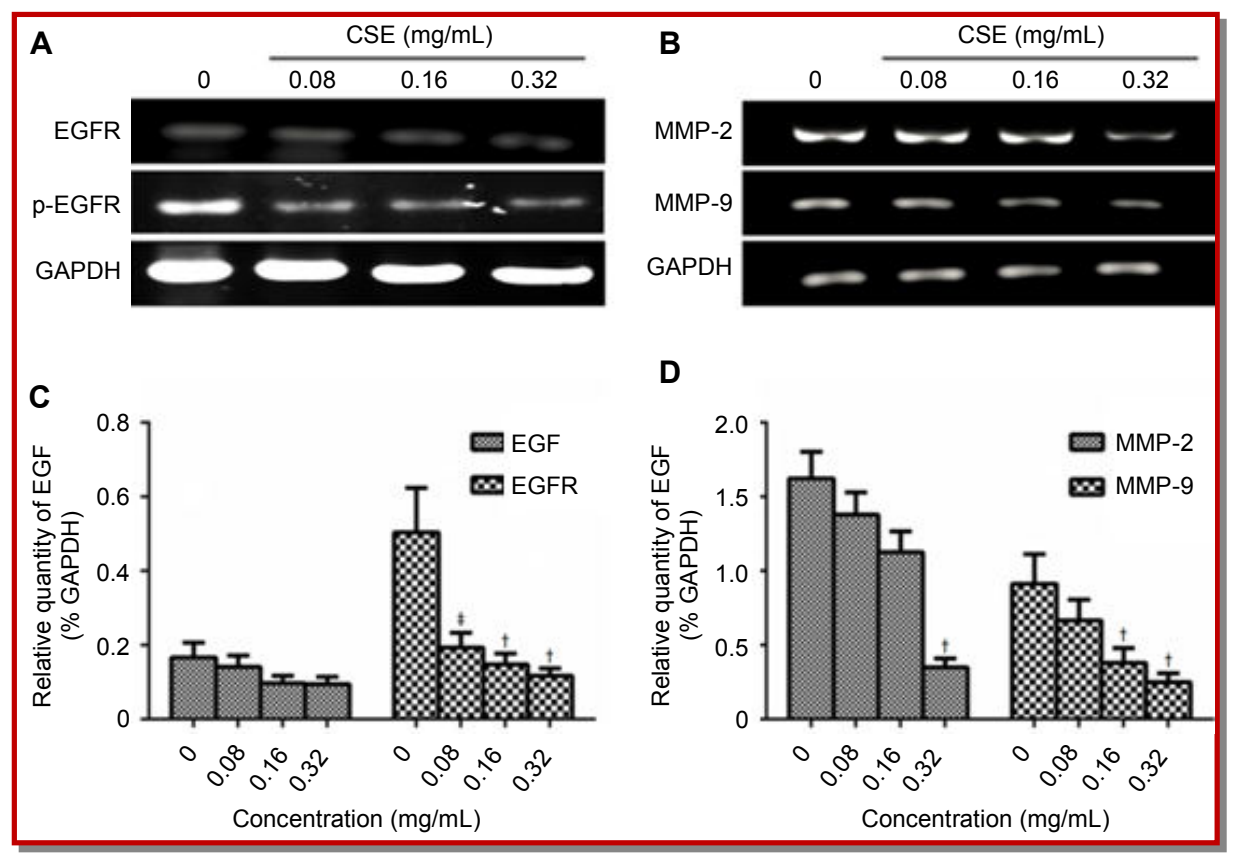

Figure 7: Effect of CSE on mRNA expression

A, EGF and EGFR mRNA expression, B, MMP2 and MMP9 mRNA expression in A431 cells treated with CSE at indicated concentrations for 48 hours indicates that CSE could regulate the mRNA levels of EGF, EGFR, MMP2 and MMP9. C and D, quantification of A and B. Data were represented as means \pm SEM at least three independent experiments. Statistically significant changes at $\neq \mathrm{p}<0.05, \mathrm{p}<0.01 \mathrm{vs}$. the control group 
A431 commonly overexpress EGFR protein, therefore our current study focuses on that CSE could inhibit proliferation of A431 cells via inducing regulation of EGFR signaling pathway, and explore the related molecular mechanism of action.

Results of cell experiments imply that CSE can markedly and concentration-dependently suppressed A431 proliferation and colony formation. Cell cycle arrest represents an effective mechanism involved in the induction of cell death (King and Cidlowski, 1998). CSE-mediated cell death in A431 cells was due to inducing a G2-phase cell cycle arrest in part.

We examined whether the effect of CSE on A431 cells influenced cell motility. The scratch motility (wound healing) and milli-cell assays indicated that CSE significantly reduced the migration of A431 cells in a dose- and time-dependent. The ability of cells to migrate through uncoated porous filters in response to a chemotactic stimulus was examined in a transwell migration assay. Treatment of CSE displayed obvious inhibition of invasion in a dose-dependent.

The molecular mechanism by which CSE affects cell proliferation by regulating of EGFR protein as well as metastasis-related protein MMP-2, and MMP-9. The expressions of MMPs against matrix macromolecules have been associated with the development of malignant phenotypes and the promotion of cell invasiveness and metastasis. CSE's anti-invasive action is also reflected by its suppressive effects on the expressions of MMP-2 and MMP-9, two major MMPs mediating the degradation of the ECM. In our study, ESMC treatment reduced the protein expression of MMP-2 and MMP-9. These results suggest that CSE's anti-invasive action is mediated, at least in part, by diminishing the ability of A431 cells to degrade the components of ECM by modulating MMP-2 and MMP9 expression.

\section{Conclusion}

CSE suppresses cell growth in high-EGFR expression cell A431 in vitro. This suggests that CSE is a potent EGFR inhibitor with the potential to become a useful agent in the treatment of high-EGFR expression cancers.

\section{Acknowledgements}

This work was supported by the Fund of Xi'an Medical University (2015DOC17, 2015DOC18, 2016GJFY07, 2016PT19), the Fund of the Educational Department of Shaanxi Province, China (16JK1666), and the Natural Science Basic Research Plan in Shaanxi Province of China (2017JQ8042).

\section{Conflict of Interest}

All authors have completed the ICMJE uniform disclosure form and declare no support from any organization for the submitted work.

\section{References}

Cao YJ, He X, Wang N, He LC. Effects of imperatorin, the active component from Radix Angelicae (Baizhi), on the blood pressure and oxidative stress in $2 \mathrm{~K}, 1 \mathrm{C}$ hypertensive rats. Phytomedicine 2013; 20: 1048-54.

Goldman B, Mach A, Wurzel J. Epidermal growth factor promotes a cardiomyoblastic phenotype in human fetal cardiac myocytes. Exp Cell Res. 1996; 228: 237-45.

Huang SM, Harari PM. Epidermal growth factor receptor inhibition in cancer therapy: Biology, rationale and preliminary clinical results. Invest New Drugs. 1999; 17: 259-69.

Hynes NE. ErbB2: From an EGFR Relative to a central target for cancer therapy. Cancer Res. 2016; 76: 3659-62.

King KL, Cidlowski JA. Cell cycle regulation and apoptosis. Annu Rev Physiol. 1998; 60: 601-17.

Lee JH, Kim IW, Kim SH, Kim MA, Yun EY, Nam SH, Ahn MY, Kang D, Hwang JS. Anticancer activity of the antimicrobial peptide scolopendrasin VII derived from the Centipede, Scolopendra subspinipes mutilans. J Microbiol Biotechnol. 2015; 25: 1275-80.

Li J, Li Y, Feng ZQ, Chen XG. Anti-tumor activity of a novel EGFR tyrosine kinase inhibitor against human NSCLC in vitro and in vivo. Cancer Lett. 2009; 279: 213-20.

Liu ZC, Zhang R, Zhao F, Chen ZM, Liu HW, Wang YJ, Jiang $\mathrm{P}$, Zhang $\mathrm{Y}, \mathrm{Wu} \mathrm{Y}$, Ding JP, Lee WH. Venomic and transcriptomic analysis of Centipede Scolopendra subspinipes dehaani. J Proteome Res. 2012; 11: 6197-212.

Ma WN, Zhang DD, Zheng L, Zhan YZ, Zhang YM. Potential roles of Centipede Scolopendra extracts as a strategy against EGFR-dependent cancers. Am J Transl Res. 2015; 7: 39-52.

Magkou C, Nakopoulou L, Zoubouli C, Karali K, Theohari I, Bakarakos P, Giannopoulou I. Expression of the epidermal growth factor receptor (EGFR) and the phosphorylated EGFR in invasive breast carcinomas. Breast Cancer Res. 2008; 10: R49.

Merlino GT, Xu YH, Ishii S, Clark AJ, Semba K, Toyoshima K, Yamamoto T, Pastan I. Amplification and enhanced expression of the epidermal growth factor receptor gene in A431 human carcinoma cells. Science 1984; 224: 417-19.

Nicholson RI, Gee JM, Harper ME. EGFR and cancer prognosis. Eur J Cancer. 2001; 37: S9-15.

Oliveira S, van Bergen en Henegouwen PM, Storm G, Schiffelers RM. Molecular biology of epidermal growth factor receptor inhibition for cancer therapy. Expert Opin Biol Ther. 2006; 6: 605-17. 
Shimamura M, Hazato T, Ashino H, Yamamoto Y, Iwasaki E, Tobe $\mathrm{H}$, Yamamoto $\mathrm{K}$, Yamamoto $\mathrm{S}$. Inhibition of angiogenesis by humulone, a bitter acid from beer hop. Biochem Bioph Res Co. 2001; 289: 220-24.

Sirkisoon SR, Carpenter RL, Rimkus T, Miller L, MethenyBarlow L, Lo HW. EGFR and HER2 signaling in breast cancer brain metastasis. Front Biosci (Elite Ed). 2016; 8: 24563.

Undheim EA, King GF. On the venom system of centipedes (Chilopoda), a neglected group of venomous animals. Toxicon 2011; 57: 512-24.
Wells A. EGF receptor. Int J Biochem Cell Biol. 1999; 31: 637-43.

Woodburn JR. The epidermal growth factor receptor and its inhibition in cancer therapy. Pharmacol Ther. 1999; 82: 24150 .

Yarden Y, Sliwkowski MX. Untangling the ErbB signalling network. Nat Rev Mol Cell Biol. 2001; 2: 127-37.

Zhan YZ, Zhang YM, Liu CC, Zhang J, Smith WW, Wang N, Chen YN, Zheng L, He LC. A novel taspine derivative, HMQ1611, inhibits breast cancer cell growth via estrogen receptor alpha and EGF receptor signaling pathways. Cancer Prev Res (Phila). 2012; 5: 864-73. 